\section{Patterns of drugs and alcohol abuse among youth}

\author{
Tamar Ruth Orowitz*
}

The Chinese University of Hong Kong, Hong Kong

\section{Abstract}

The study attempted to answer several questions: Does the cultural and social background of immigrant youth from the Former Soviet Union (FSU) affect their use of addictive substances? Do these youth show distinctive patterns of drug and alcohol abuse? Do the addictive substances used by these teenagers share similar characteristics? Are the patterns of drug abuse and alcohol abuse different? Do students in different educational frameworks demonstrate different consumption patterns? Can "critical moments" explain the presence or absence of alcohol and drug abuse?

\section{Introduction}

The study is framed by two theoretical paradigms: the Social Problem paradigm and the Normalization paradigm $[1,2]$, and employs a variety of research methods. These methods include in-depth interviews with 53 adolescents in different educational settings, 45 in-depth interviews with parents, and 3 focus groups in informal youth education settings. Questionnaires were also administered to 285 male adolescents in four categories of educational frameworks: mainstream schools, vocational schools for low achievers, programs for at-risk youth, and rehabilitation programs for youth who are heavy users. The questionnaires employed standard tools or tools used in previous research, especially research regarding the integration of immigrants from the FSU [3].

According to the research findings for alcohol consumption, three quarters of the boys had consumed alcohol in the last year, and one third consumed alcohol more than once a week. One third of the boys reported that they had consumed more than 4 drinks the last time they consumed alcohol. Approximately one third of the boys had been drunk at least four times in their lives, and half the boys obtained high scores on the measure of binge drinking developed for the research that was weighted for frequency and level of alcohol consumption. As for the type of drugs used, the most common drug used by the boys was cannabis: just under one third said they had used some cannabis during the past year, and most had used it more than once (i.e., on more than three separate occasions). In programs for at-risk youth and poor-achievers, one tenth of the boys reported using cannabis more than 25 times in the past year.

\section{More Information}

*Address for Correspondence: Tamar Ruth Orowitz. Department of Education Ben Gurion University, Tel: 0506462482 ; Email: tamarh@bgu.ac.il

\section{Submitted: December 09, 2020}

Approved: March 18, 2021

Published: March 19, 2021

How to cite this article: Orowitz TR. Patterns of drugs and alcohol abuse among youth. J Addict Ther Res. 2021; 5: 012-013.

DOI: 10.29328/journal.jatr.1001016

Copyright: (c) 2021 Orowitz TR. This is an open access article distributed under the Creative Commons Attribution License, which permits unrestricted use, distribution, and reproduction in any medium, provided the original work is properly cited.

W) Check for updates

OPEN ACCESS
One tenth of the boys also reported using ecstasy at some time and three-quarters had used the drug on more than three occasions. Most of these boys were in the at-risk group.In addition, the percentage of boys who used cocaine and inhalants were higher compared to compared to earlier survey's findings and one-fifth of the boys reported using inhalants occasionally.

A comparison of drug use patterns in the various types of schools showed differing patterns of drug and alcohol consumption. This drugs and alcohol were less frequently in mainstream schools, more prevalent in schools for lowachievers, and most prevalent in schools for at-risk youth. Youth in special programs for heavy users reported the highest level of past consumption of drugs and alcohol. There was a certain similarity regarding the use of certain substances between the boys in mainstream schools and those in programs for low achievers. When asked why they thought teenagers used drugs and alcohol, the boys pointed to three main contributors: peer pressure, escapism and wanting to feel high, and exploring boundaries. The boys in mainstream schools and those who did not use alcohol or drugs tended to blame social pressure, while boys in programs for heavy users and boys who consumed some form of substance tended to highlight escape for reality and the feeling of euphoria.

The analysis of measures relating to the boys' personal characteristics revealed that the boys in facilities for atrisk youth had the lowest self esteem and were the most adventure-seeking, and that the boys in programs for heavy users were the most adventure-seeking. The characteristics 
examined - salutogenic disposition, self-image, adventure seeking, and ethical attitudes - were all found to be correlated with drug use, whereas a high degree of adventure seeking was found to be correlated most strongly with excessive alcohol consumption.

The interviews with participants showed that a large percentage had complex family situations, which for some had been like that in Russia, but for others stemmed from the crisis of immigrating to Israel. Although some of these youngsters functioned in the higher post-elementary grades and apparently coped with their new situation, others had "crossed the Rubicon" and were considered "at risk" [4]. However, many of the teenagers indicated empathy for their parents', and above all their grandparents', experiences of immigration, and indicated a positive attitude toward family values, and a relaxed atmosphere at home. Interviews with boys' parents showed the parents to be generally more accepting about the social integration process, less distressed about it than their children, and that they focused on making a living and employment.

The study also demonstrates the family's' considerable role in the youngsters drinking and drug related nonnormative behavior and family parameters such as family conflict, financial distress, slow social integration, and weak family values. The research also found parents to be relatively tolerant toward drinking.

The boys had also been transferred to many different schools,. However, in all types of schools examined by the study, the boys' self-image as students was positive and many thought that immigrants from the FSU had better chances of success than other immigrants and veteran Israelis. One third admitted having behavior problems and ADHD. Most of the boys took responsibility for their behavior at school, and the main factor they believed might improve their school performance was investment in themselves, and only after that investment in external parameters. The research also found that the boys changed schools so often partly because the schools were unable to deal with the immigrants, and conflicts erupted between the boys and their teachers and the boys and the other students, and partly at their own initiative. Some boys drew strength and support from the neighborhood or social framework for immigrants, whereas others relied on their own inner resources.

Regarding the boys' relations with the same age peers and their leisure activities, the interview analysis showed that the youth formed groups of temporary, non-binding cliques, which could be antagonistic toward other groups, especially veteran Israelis. These cliques offer the youth status, experience, relevance and security, as well as a pastime. One of the key features of behavior is the "parks" culture, namely, the public parks where the cliques gather and consume alcohol and other substances.

The questionnaires demonstrated that youth in programs for at-risk teens and low achievers spend more time in parks and at trance and acid parties that the others; they also reported hanging out with older friends, when asked what comforts/frustrates them. The boys from the mainstream schools had a greater tendency to ask their mothers and same age friends for help. Most of the boys interviewed felt that their friends had a negative opinion regarding drug use, but a positive view regarding alcohol consumption, or no view at all. When asked about belonging and identification with their environment, most boys were moderately satisfied with their neighborhood and defined themselves as Israelis or Russians, only a few defined themselves as Jews [5].

A comprehensive regression analysis was also performed on a variety of quantitative research variables. The analysis identified three significant variables in the general model which influence cannabis consumption: low self esteem, behavioral problems at school, and motivation to study.

Five variables were found to affect heavy drinking: self-esteem, behavioral problems, adventure-seeking, selfdetermination as a student and Russian identity [6].

\section{References}

1. Jones A. Problems in the school. In Jones A, Connor, DW Powell De eds, soviet soviet social problem. 1991; 213-227.

2. Juviller $\mathrm{PH}$. No end of a problem, perestroika for family. In jones a connor, DW, Powell DE, EDS .SOVIET social problem. 1991; 94-113.

3. Fisher M. soviet youth and culture. In Riorden J. ED, Soviet youth culture. 1989; 1-5.

4. Beck U. Risk Society Towards a New Modernity. London sage Publication. 1992

5. Reserch Advisor. The National Anti-Drug Authority of Israel. Dr. Rachel Bar Hamburder.

6. Konstantinovski D. Youth and Education in a changing Society. In Horowitz T, Kotik-Friedgut B, Hoffman S. (Eds). From pace Makers to Dropouts. 2003; 42-69. 